\title{
Planejamento Estratégico Situacional
}

\author{
Itiro Iida
}

Doutor em Engenharia, Assessor de Planejamento do CNPq

SQN 209, Bloco J, Apto. 606, CEP 70854-100) - Brasília, DF

Palavras chaves: planejamento tradicional, planejamento estratégico situacional, cenários, fluxograma funcional.

Key words: traditional planning, situational strategic planning, scenariu, situational flowchart.

\section{RESUMO}

Apresenta-se a técnica de Planejamento Estratégico Situacional, em comparação com us métodos tradicionais de planejamento. Esse novo método de planejamento é aplicável a sistemas complexos, como as organizações sociais, sujeitos a diversos tipos de incertezas.

\begin{abstract}
The technique of Situational Strategic Planning is presented in comparison with the traditional planning methods. This new method is applicable to complex systems. like social organizations, subjected to several types of uncertainties.
\end{abstract}




\section{Introdução}

A solução de um problema depende de seu correto entendimento e da formulação de um modelo adequado para interpretá-lo. Do contrário, arrisca-se a tratar apenas dos sintomas, scm erradicar as suas causas, ou resolvê-lo apenas parcialmente. Tudo isso pode significar um enorme desperdício de tempo e de recursos. Problemas não resolvidos no momento adcquado podem agravar-se, no futuro, gerando crises que passam a exigir providências urgentes. Em consequência, muitos dirigentes passam a maior parte do tempo cuidando dessas urgências, sem que o problema real scja solucionado.

Problcmas complexos não podem ser resolvidos com modelos demasiadamente simples, que cscamoteiem a realidade. É necessário usar modelos adequados, capazes de espethar essa complexidade.

Os métodos tradicionais de planejamento são simplcs, mas inadequados para analisar e acompanhar sistemas complexos. A maioria dos problemas administativos, econômicos e sociais cai nesta categoria. Para tais casos, desenvolveu-se, recentemente, o método de Planejamento Estratégico Situacional ou, abreviadamente, PES. Ele é flexível e se adapta às constantes mudanças da situação real. E, o mais importante. não separa as funções de plancjamento das de execução, pois não opera com "reccitas" prontas, mas realiza análises situacionais para orientar o dirigente no momento da ação.

\section{Do Planejamento Tradicional para 0 Estratégico}

Os métodos tradicionais de planejamento foram difundidos na América Latina a partir da década de 50 pela Cepal c outros órgãos. Desde então, têm sido bastante aplicados, inclusive em situações onde não são recomendados. Geralmente, apresentam um conteúdo tecnocrático e determinístico, baseando-se nas seguintes premissas:

a) o futuro é projetado a partir de um diagnóstico do passado; o plano assume implicitamente que a trajetória passada se repetirá no futuro, com poucas mudanças:

b) o objeto do plano é estático: pressupõese que quem clabora o plano tem todos os poderes para atuar sobre o objcto do plano, o qual é considerado passivo:

c) há uma separação entre a equipe de planejamento $\mathrm{c}$ a de execução, no momento da ação, o plano acaba sendo esquecido ou abandonado, porque não oferece oricntações seguras ou fíca desatualizado logo no início da ação e o dirigente passa para as inevitáveis improvisações.

Essas caracteristicas tornam o planejamento tradicional pouco potente para resolver problemas complexos e. quando são aplicados erroneamente a esses casos, frequentemente apresentam desvios de 100 a $300 \%$ entre o planejado e o real.

O Plancjamcnto Estratégico Situacional PES - foi desenvolvido pelo cconomista chiIeno Carlos Matus, a partir da década de 70), como um método mais flexível, permitindo 
trabalhar com a complexidade dos problemas sociais. Neste método, o futuro não é determinístico e a realidade é continuamente acompanhada. Quando houver uma mudança da situação rcal. o plano é imediatamente ajustado.

O PES se assemelha a um jogo de xadrez, onde sempre se joga "contra" o outro. O mesmo é elaborado sob o ponto de vista de um dos jogadores (eu), que deve jogar com o "outro". Cada jogada é precedida de uma análisc situacional, para se buscar a jogada mais efetiva naqucle momento. Esta efetividadc vai depender não apenas da minha decisão, mas também da reação do outro. Este pode reagir de forma inesperada $c$ anular uma jogada que, aparentemente, era boa. Ou seja. o objeto do plano não é passivo e realiza também as suas próprias jogadas.

\section{Diferenças entre o Planejamento Tradicional e o Estratégico}

O plano tradicional é do tipo normativoprescritivo e é genérico. O PES é elaborado sempre do ponto de vista de um determinado jogador $\mathrm{c}$ consiste de uma cadeia de jogadas que dependem das circustâncias. A figura de planejador não cxistc no $\mathrm{PES}$, pois este se confunde com o próprio executor das ações ou das jogadas. E ncm tampouco existe um plano acabado. No momento da ação é que se decide a prática do PES, de modo que o plano só se completa na ação. O diagnóstico, usado no planejamento tradicional, é substituído pela apreciação situacional, que é realizada continuamente. ao longo do plano. Essa apreciação é feita pelo próprio jogador ou por uma assessoria tecnopolítica especializada, abrangendo não apenas a análise da situação, mas fazendo também conjecturas sobre as possíveis reaçõcs do outro. A Fig. 1 apresenta um resumo dessas diferenças.

Existe a famosa historinha do jogador Garrincha, na copa mundial de futebol de 1958 . O tćcnico Vicente Feola deu instruções aos jogadores, antes da partida contra a Inglaterra, mais ou menos nos seguintes termos: "Nilton Santos toma a bola do adversário, no meio do campo, e passa para o Garrincha, que dribla os zagueiros c centra para o Pelé chutar ao gol" No quc Garricha retricou: "E o adversário já foi avisado disso?" Feola provavelmente era adepto do planejamento tradicional, e o Garrincha, do PES. O plancjamento tradicional falha justamente ao considerar o outro como estático ou de comportamento determinístico, e eu, o planejador, tendo todos os poderes para realizar tudo que imaginar

\begin{tabular}{|l|l|l|}
\hline \multicolumn{1}{|c|}{ FATOR } & PLANO TRADICIONAL & \multicolumn{1}{c|}{ PES } \\
\hline 1. Objeto do plano & Passivo & Ativo e complexo \\
\hline 2. Explicação da realidade & Baseada em diagnósticos & Apreciação situacional \\
\hline 3. Concepção do plano & Normativo-prescritivo & Jogadas sucessivas \\
\hline 4. Análise estratégica & Consultas a especialistas & Análise da viabilidade \\
\hline 5. Fatores & Genéricos & Especifico \\
\hline 6. Operação & Ação separada do plano & Mediação entre o plano e a ação \\
\hline
\end{tabular}

Fig. 1. Diferenças entre o plano tradicional e o estratégico situacional. 


\section{A Técnica dos Cenários}

Pode-se fazer uma analogia do PES com o teatro. As diversas realidades são chamadas de cenários. Em cada cenário existe a paisagem e os atores. A paisagem é a parte fixa ou pouco mutável do cenário (como organizações, estruturas e funções que pouco se alteram durante o projeto). Os attores ou jogadores são aqueles que executam as ações ou jogadas. Estas se realizam dentro de certas regras estabelecidas, que podem ser leis, normas, regulamentos, preceitos, costumes, princípios, tradições ou crenças.

Para realizar uma jogada, o ator precisa ter certas "cartas na mão", chamadas de acumulações c representadas por conhecimentos pessoais, poder econômico, poder politico, liderança, domínio formal de organizações e outros recursos de que pode se valer o jogador, no momento da jogada. As jogadas são chamadas defluxos e representam as ações ou movimentos que se realizam dentro das regras, usando as acumulações. Fazendo-se analogia com um sistema produtivo, acumulação ć o capital e o fluxo, o trabalho.

As jogadas são sempre realizadas contra algum outro jogador, que pode ser uma outra pessoa, um grupo, uma instituição ou um sistema que, por sua vez, também reagem $\mathrm{c}$ produzem as suas jogadas. Não de pode esperar, entretanto, que as jogadas do outro sigam o mesmo padrão das minhas.

Por excmplo. o General Galtieri, Presidente da Argentina, antes de invadir as Ilhas Malvinas, em 1982, perguntou-se: "Quanto valem as Malvinas para os argentinos?" Resposta: "Muito". Fez a mesma pergunta para o outro: "Quanto valem as Malvinas para os ingleses?" Resposta: "Quase nada". Baseado nisso, estimou que os ingleses não mobilizariam a frota naval por $13 \mathrm{mil} \mathrm{km}$, a um custo enorme, para defender algumas ilhotas vulcânicas, praticamente sem nenhum valor econômico. Entrctanto, a Primeira Ministra Margareth Thatcher, precisando afirmar-se politicamente, não poderia permitir que o seu território fosse simplesmente invadido por uma potência mais fraca. Então, a pergunta correta seria: "Qual é o custo político para Thatcher deixar-se invadir por uma potência mais fraca?" Resposta: "Enorme". Este exemplo evidencia que o jogo do PES não é simétrico, ou seja, nem todos os jogadores seguem as mesmas regras.

Cada jogo tem uma história, regras, acumulações e fluxos. A história do jogo define quem são os atores relcvantes e cria condições para a entrada de novos jogadores e a saída dos antigos. Entram no jogo aqueles que ganham uma aposta em outro jogo e saem os que perdem apostas no jogo em que estão participando. Os jogadores produzem acumulações durante o jogo ou as recebem de jogos anteriores. Essas acumulações determinam o poder do jogador ou a capacidade de produzir jogadas. Quando um jogador ganha, aumenta a sua acumulação. Se perde, diminui-a e, portanto, o seu poder de fazer novas jogadas. Perdendo diversas jogadas sucessivas, pode ser excluído do jogo por falta de acumulação para fazer novas jogadas.

Pode ocorrer uma reforma no jogo quando um jogador ganha bastante acumulação para fazcr algumas jogadas ou uma cadeia de jogadas para mudar as regras do jogo. Note que o jogador faz as suas jogadas dentro das regras antigas, atć obter acumulação suficiente. Se esse jogador introduzir mudanças profundas nas regras, diz-se que fez uma revolução e, neste caso, o velho é dominado pelo novo. 
Organizações que funcionam mal, desleixadamente, sem monitoramento e nem cobranças de desempenho, são governadas por regras de baixa responsabilidade dos seus dirigentes. Nesse caso, só é possível reformulá-las se essas regras forem substituidas por outras, de alta responsabilidade. As experiências comprovam que, sem essa mudança na cúpula da organização, todos os demais esforços para introduzir melhorias podem estar fadados ao fracasso.

\section{Governabilidade}

Diz-se que um ator tem governabilidade sobre um problema quando controla os recursos necessários para realizar as jogadas. Do contrário, ele não terá governabilidade, mas pode fazer demandas junto a outro ator que tenha essa governabilidade. Caso esse outro seja da oposição e, portanto, sem chances de aderir ao projeto do ator, resta denunciá-lo.

O espaço do problema é classificado em três zonas, de acordo com o critério de governabilidade:

Zona I - Espaço de governabilidade. É o espaço onde se situam as regras, acumulações e fluxos sobre os quais o ator do problema tem governabilidade.

\section{Zona Il - Espaço fora de governabilida-}

de. É o espaço onde se situam as regras, acumulações e fluxos fora de governabilidade do ator, mas que fazem parte do problema.

Zona III - Espaço fora do jogo. São as regras, acumulações e fluxos fora do jogo, mas que podem influenciá-lo.

\section{Incertezas}

No modelo tradicional de planejamento, dado o seu caráter determinístico, pode-se traçar o caminho entre o estado inicialA para o estado desejado B. Já no modelo estratégico, podem ocorrer vários resultados possiveis: B1, B2, B3, ..., Bn (ver Fig. 2). Esses resultados são influenciados por "acidentes" de percurso, chamados de incertezas.

Por exemplo, um veleiro deve sair do porto A para levar turistas para o outro lado da baía (Fig. 3). Entretanto, o capitão do veleiro não pode escolher livremente o seu destino, pois o mesmo depende das condições do tempo durante o percurso. Se houver vento favorável, ele escolhe o destino B3, onde se situam as melhores praias. Contudo, se os ventos forem fracos ou contrários, cle deve escolher, respectivamente, os pontos B2 ou B1. Portanto, dadas essas incertezas, o capitão nâo pode garantir, deterministicamente, o seu porto de chegada.

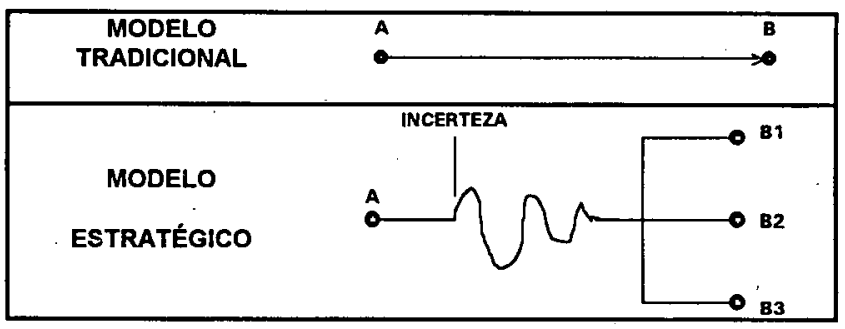

Fig. 2. Diferenças entre os modelos tradicional e estratégico. 


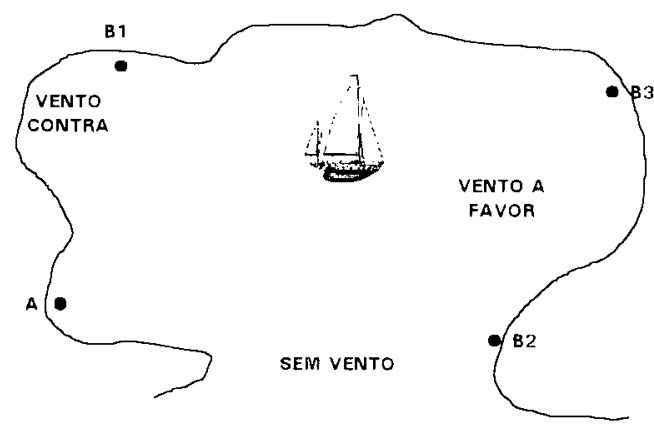

Fig. 3. A trajetória do veleiro depende de variáveis fora de controle do capitão.

Quando essas incertezas são de baixa probabilidade de ocorrência, mas que podem provocar grandes impactos quando ocorrem, são chamadas de surpresas. Em política intcrnacional foi surpresa, por exemplo, a rápida queda da URSS cm 1991, que poucos analistas políticos ousaram prever.

\section{Definição do Problema}

Todo problema social é de natureza situacional, ou scja, depende de quem o considere como sendo um problema. O que é problema para um, pode ser uma oportunidade para outro. Por excmplo, o narcotráfico ć um grande problema para a polícia, mas um negócio lucrativo para os traficantes. Para estes, o problema ć justamente a policia. Portanto, no PES, o ator que declara o problema deve ficar bem definido.

É necessário também, delimitar o espaço do problema para descrever a governabilidade do ator. Por cxemplo. vamos supor que o problema scja o comportamento agressivo dos adolescentes. Se o ator for o pai, a governabilidade pode estar dentro da casa. Já, se for a policia. o mesmo pode intervir em bailes funk ou $\mathrm{cm}$ gangs de rua.

\section{Construção do}

\section{Fluxograma Situacional}

O fluxograma situacional é uma represcntação gráfica do modelo explicativo do problema. Para construi-lo, a primeira providência é descrever o problema usando um conjunto de frases curtas. chamadas de descritores. Esse conjunto dere ser necessário e suficiente para precisar o contcúdo do problcma. e não deve referir-se nem a causas e ncm a consequências do mesmo. Para lestar se os descritores cstão bem formulados, faz-se a pergunta: caso scjam climinadas as cargas negativas dos descritores, o problema seria resolvido? Se a resposta for afirmativa. cle estará bem descrito. Se for negaliva. é possi$v \mathrm{cl}$ que esteja faltando algum descritor ou que os descritores cscolhidos não scjam relcvantes.

Por cxemplo, o problcma "a familia de José passa fome" poderia ter os seguintes descritores:

$\mathrm{d} l=$ membros da familia de José comem só uma vez por dia:

$\mathrm{d} 2=$ a dicta é de má qualidade. contendo apenas metade dos valores proteico c calórico necessários

Com basc nesses descritores. passa-se à construção do fluxograma situacional. scguindo as seguintes ctapas:

a) escolhe-se um conjunto de argumentos. que são as principais causas que se relacionam com os descritores: para cfeitos práticos. não devem ser sclecionados mais de 20) argumentos:

b) cada argumento deve ser descrito com 
frases curtas e precisas, como: sistema tributário deficiente; falta treinamento aos jogadores;

c) os argumentos devem ser classificados em regras, acumulações ou fluxos, e distribuidos nas zonas de governabilidade I, II ou III.;

d) arranjam-se os argumentos em uma matriz e estabelecem-sc as relações de causalidade entre os mesmos, de trás para frente, ou seja. dos descritores para as regras; estas rclações são representadas por flechas, cujos sentidos indicam a direção de causalidade;

c) todos os argumentos situados na Zona I ou Zona II devem ter alguma causalidade de cntrada c outra de saída, excetuando-se as regras, que podem ter só saidas e nenhuma cntrada;

f) na Zona III , as causas só têm saídas e as consequências só entradas, interrompendo-se as cadcias de causalidade nesta zona; $\mathrm{e}$

g) nenhum argumento pode situar-se de forma ambigua, seja fora das zonas I, II ou III, ou mesmo na interseção das células da matriz.

Para melhor cntendimento desta técnica. vamos desenvolver um exemplo ilustrativo, para o caso de um time de futebol. O time azul tem apresentado resultados irregulares e tem ocorrido diversos atritos entre os jogadores e dirigentes. que se acusam mutuamente. $\mathrm{Na}$ última rodada, o time azul perdeu por 3 a 0 para uma cquipe mais fraca e os ânimos se acirraram. Os descritores deste problema podem ser formulados da seguinte forma

$\mathrm{d} l=$ time azul perde por 3 a 0

$\mathrm{d} 2=$ atritos entre dirigentes e jogadores

A partir desses descritores, foram selecio- nados 8 argumentos, sendo 5 deles no espaço de governabilidade. 2 fora de governabilidade e 1 fora do jogo. Partindo-sc dos descritores, foram desenhadas as relações de causalidade, de trás para frente. relacionando os argumentos entre si. Fica assim elaborado o fluxograma situacional do time azul, tendo o Presidente do time azul como ator. (Ver Fig. 4).

O próximo passo é a identificação dos nós críticos, que são aqueles argumentos que satisfazem simultaneamente a três condições:

a) representam um centro prático de ação, ou seja, o ator (ou outros atores) pode atuar diretamente sobre estas causas, de modo efetivo: inversamente, um argumento não é um nó crítico quando for uma simples consequência de argumentos anteriores:

b) aprescntam um alto grau de impacto sobre os descritores - a análise de sensibilidade é feita mudando-se o conteúdo dos argumentos e avaliando-se o impacto deles sobre os descritores; $\mathrm{c}$

c) é politicamente oportuno atuar sobrc o argumento, implicando em um juizo prévio de viabilidade, por parte do ator

No cxcmplo do time de futcbol. trôs argumentos foram considerados nós críticos, por satisfazerem às condições acima:

NCl - Atraso no pagamento do time azul

NC2 - Time azul com mau preparo físico

NC3 - Time azul desmotivado.

Isso significa que o Presidente do time azul (ou outros atores) deverá atuar sobre esses três nós críticos para melhorar o desempenho 
ÂMBITO TEMÁTICO: JOGO DE FUTEBOL

PROBLEMA: FRACO DESEMPENHO DO TIME AZUL

ATOR: PRESIDENTE DO TIME AZUL

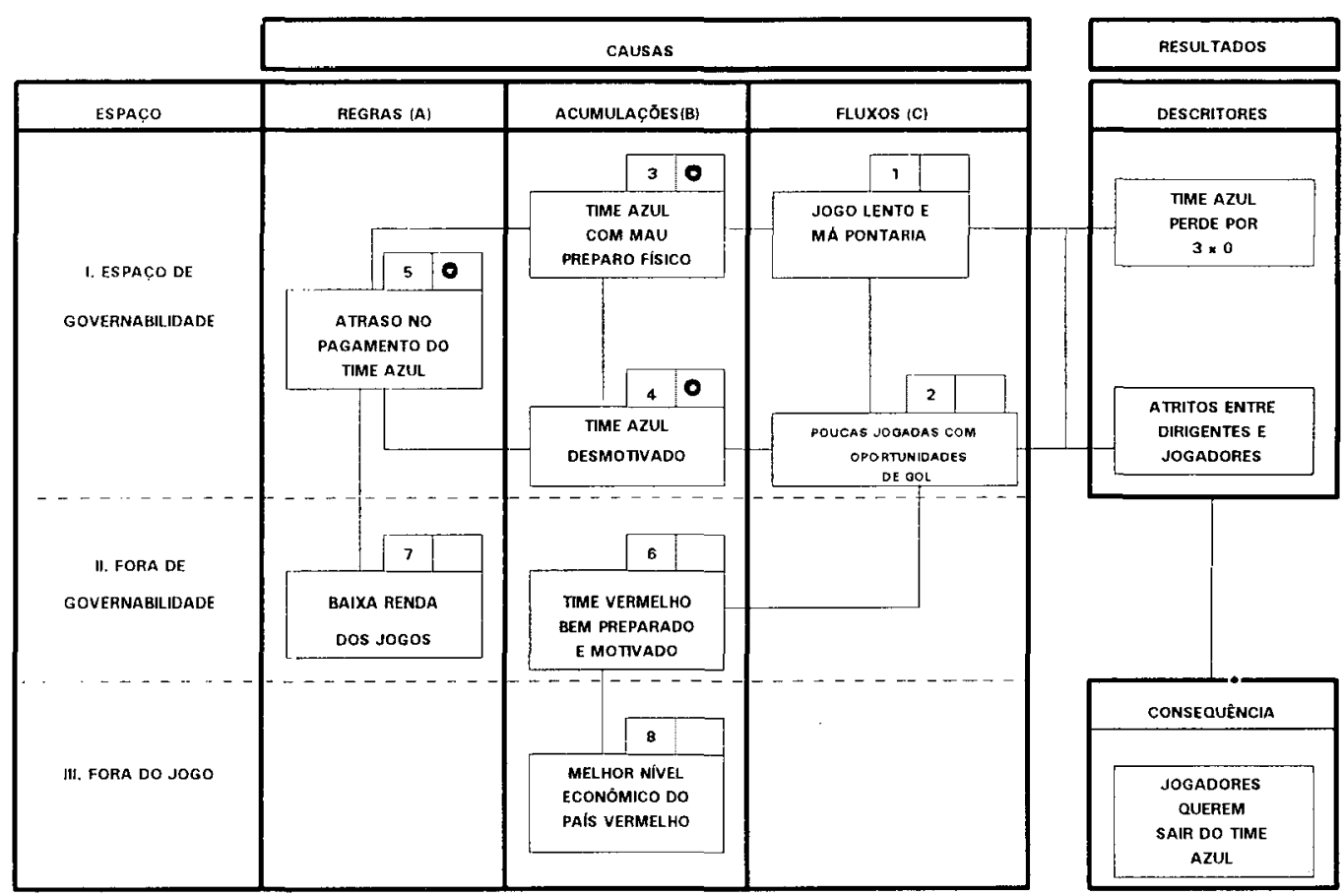

Fig. 4. Exemplo de fluxograma situacional. $O$ sinal " $O$ " indica nó crítico.

do time. Admitindo-se que o fluxograma situacional esteja bem construído e os nós críticos corretamente identificados, qualquer atuação fora desses nós será pouco efetiva, não provocando impactos significativos sobre os decritores do problema e, portanto, não solucionando o problema.

Para continuar a análise, constroi-se uma versão simplificada do fluxograma situacional, chamada de árvore do problema, onde figuram apenas os nós críticos e os descritores (ver Fig. 5). Todos os demais argumentos são esquecidos, para que a atenção possa se con- centrar somente nos nós críticos.

Por exemplo, o argumento 2: "poucas jogadas com oportunidades de gol" (ver Fig. 4) foi eliminado por não ser um nó crítico. Supondo que o ator não soubesse disso, poderia conceber a operação: "treinar chutes a gol". Entretanto, isso resultaria apenas no desgaste dos jogadores e em perda de tempo, pois não resolveria o problema, porque não produz impacto sobre os descritores. Naturalmente, essa mesma operação poderia ser considerada crítica, em um outro problema, com diferentes descritores. 


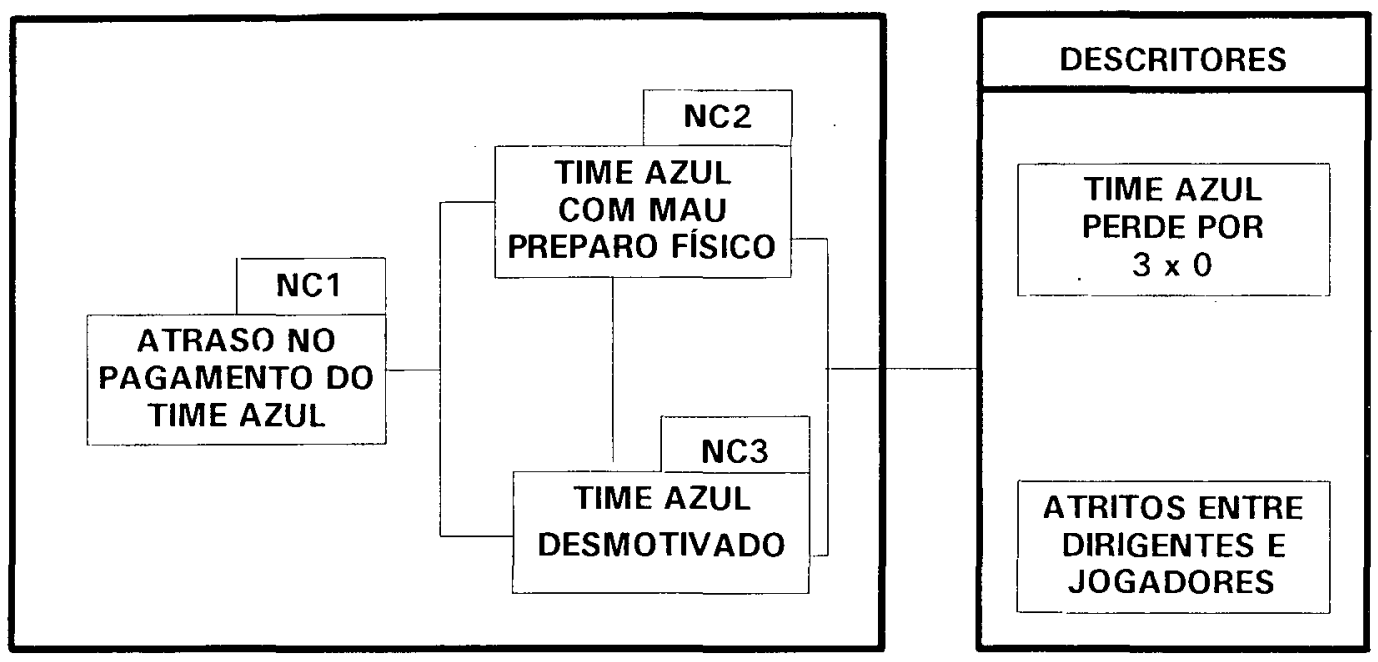

Fig. 5. Excmplo de árvore do problema, contendo apenas nós críticos.

\section{Atuação sobre o Problema}

Para atuar sobre o problema, formulam-se algumas operações, que são as ações capazes de modificar o estado de algum nó crítico e, assim, produzir impacto sobre os descritores do problema. No exemplo considerado, podem ser concebidas as seguintes operações:

OP1 - Conseguir empréstimos para fazer pagamentos atrasados

OP2 - Reformular o sistema de condicionamento físico dos jogadores

OP3 - Promover reuniões entre jogadores e dirigentes para resolver os atritos

OP4 - Conseguir patrocínio para arcar com parte dos custos

OP5 - Punir jogadores que manifestarem descontentamentos

A seguir, listam-se os recursos necessários para se realizar estas operações. Estes nem sempre se referem a bens materiais ou monetários. Podem ser conhecimentos pessoais. determinadas habilidades, liderança, influências políticas, controle de organizações e outros. No exemplo considerado, vamos supor que sejam necessários os seguintes recursos:

rl - Recursos financeiros do clube

r2 - Crédito junto aos bancos

r3 - Prestígio junto aos patrocionadores

r4 - Contrato dos jogadores

r5 - Condicionamento físico dos jogadores

r6 - Controle disciplinar dos jogadores

Listam-se também os atores que detêm algum tipo de controle sobre esses recursos e que, portanto, podem influir na solução do problema. No exemplo, vamos supor que os atores relevantes sejam os seguintes:

Al - Presidente do time azul

A2 - Técnico de futebol

A3 - Preparador físico do time

A4 - Chefe da torcida organizada

A5 - Lider dos jogadores

A seguir, constroem-se três matrizes, relacionando as variáveis acima cntre si. 
Matriz de motivaçōes. Em geral, nem todos os atores concordam com todas as operaçoocs. O usual ć que hajam alguns atores defendendo determinadas operações, cnquanto outros $1 \mathrm{a} z \mathrm{~cm}$ oposição ou permanecem indiferentes. Essas polarizações dos atores cm relação às opcraçõcs são avaliadas na matriz de motivaçōcs (Fig 6).

\begin{tabular}{|c|c|c|c|c|c|}
\hline \multirow{2}{*}{ ATORES } & \multicolumn{5}{|c|}{ OPERAÇŌES } \\
\cline { 2 - 6 } & OP1 & OP2 & OP3 & OP4 & OP5 \\
\hline A1 & + & + & + & + & + \\
\hline A2 & & + & & & $(-)$ \\
\hline A3 & & $(-)$ & + & & $(-)$ \\
\hline A4 & & & & + & \\
\hline A5 & + & & + & & $(-)$ \\
\hline
\end{tabular}

Figg. 6. Matriz de motivaçẽes. O sinal (+) indica apoio c o (-) oposição dos atores em relação às operaçōes.

Matriz de recursos necessários. Avaliam-se os rccursos necessários a cada operação (Fig. 7).

\begin{tabular}{|c|c|c|c|c|c|}
\hline \multirow{2}{*}{ RECURSOS } & \multicolumn{5}{|c|}{ OPERAÇŌES } \\
\hline & OP1 & OP2 & OP3 & OP4 & OP5 \\
\hline $\mathrm{r} 1$ & \multirow{3}{*}{${ }^{4}$} & & & & \\
\hline r2 & & & & & \\
\hline 13 & & & & 17) & \\
\hline 14 & & & 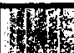 & & \\
\hline r5 & & 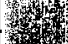 & & & \\
\hline r6 & & & & & 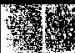 \\
\hline
\end{tabular}

Fig. 7. Recursos necessários para as operaçōes.

Matriz de controle dos recursos. Avaliam-sc as intensidades relativas dos controles que os atores exercem sobre os recursos
(Fig. 8). Obscrve que todas as somas verticais somam $100 \%$.

\begin{tabular}{|c|c|c|c|c|c|c|}
\hline \multirow{2}{*}{ ATOR } & \multicolumn{6}{|c|}{ RECURSOS } \\
\cline { 2 - 7 } & $\mathbf{r 1}$ & $\mathbf{r}$ & $\mathbf{r 3}$ & $\mathbf{r 4}$ & $\mathbf{r 5}$ & $\mathbf{r 6}$ \\
\hline A1 & 70 & 90 & 80 & 20 & & 20 \\
\hline A2 & 10 & & & 40 & 20 & 50 \\
\hline A3 & & & & 20 & 70 & 10 \\
\hline A4 & 20 & 10 & 10 & 10 & & \\
\hline A5 & & & 10 & 10 & 10 & 20 \\
\hline SOMA & 100 & 100 & 100 & 100 & 100 & 100 \\
\hline
\end{tabular}

Fig. 8. Controle dos atores sobre os recursos.

\section{Análise de viabilidade}

A análise de viabilidade é feita a partir das três matrizes acima (Fig. 6, 7 e 8). Em geral, $n \mathrm{~cm}$ todas as operações são viáveis na situação inicial (hoje) porque podem existir atores que se opõem a determinadas operações. controlando recursos $\mathrm{cm}$ montante superior aos dos atores que the são favorávcis. Colocamse, então, duas questões:

1. Qual é a parte do plano viável hoje?

2. Como se pode construir a viabilidade futura da parte do plano que não é viável hoje?

Para verificar a viabilidade de uma operação, examina-se a motivação dos atores em relação a essa operação, os recursos necessários para a operação, e os controles que os atores exercem sobre esses recursos. Por exemplo, no caso da operação OP2, os atores $\mathrm{Al} \mathrm{c}$ A2 são favoráveis, mas há oposição do ator $\mathrm{A} 3$ (ver Fig. 6). Os recursos necessários são r5 c r6 e, então, pode-se calcular o balanço dessa 
opcração (Fig. 9), utilizando-se os valores rclirados da Fig. 8

\begin{tabular}{|c|c|c|c|c|}
\hline \multicolumn{2}{|c|}{ OP2 } & \multicolumn{2}{|c|}{ RECURSOS } & \multirow{2}{*}{ SOMA } \\
\cline { 3 - 5 } \multicolumn{2}{|c|}{} & r5 & r6 & \\
\hline \multirow{2}{*}{ APOIO } & $+A 1$ & & 20 & 20 \\
\cline { 2 - 5 } & $+A 2$ & 20 & 50 & 70 \\
\hline REJEIÇĀO & $-A 3$ & -70 & -10 & -80 \\
\hline \multicolumn{2}{|c|}{ SOMA } & -50 & +60 & +10 \\
\hline
\end{tabular}

Fig. 9. Balanço de viabilidade da operação 2 na situação inicial.

Calculando-se os balanços para as demais opcrações. obtém-se o quadro apresentado na Fig. 10. Por esse quadro, observa-se que a opcração que conta com maior apoio é a OP1, c aquela mais desfavorável ć a OP5. As operações OP3 c OP4 também são viáveis. A operação OP2, cmbora seja viável, pode tornar-se conflitiva, devido à oposição do ator A3, que controla parcela significativa dos recursos nccessários à mesma (ver Fig. 9).

\begin{tabular}{|c|c|}
\hline OPERAÇōES & BALANÇO \\
\hline OP1 & 250 \\
\hline OP2 & 10 \\
\hline OP3 & 1100 \\
\hline OP4 & 90 \\
\hline OP5 & -60 \\
\hline
\end{tabular}

Fig. 10. Balanço das operaçōes na situação inicial.

Naturalmente, essas matrizes não são estáticas no tcmpo $c$ podem sofrer altcrações a cada jogada. O ator A3, por exemplo, que é contrario à operação OP2, pode mudar de opinião, caso a operação OPl seja executada com sucesso ou pode até ser convencido pelo ator A I. Contudo, a viabilidade de uma operação pode ser buscada intencionalmente, como se verá a seguir.

\section{Construção da}

viabilidade

Os atores podem reagir diferentemente frente a uma inviabilidadc. Estas reaçõcs geralmentc recaem nos seguintes casos:

a) aceitar as restrições e fazer só aquilo que for possivel, ou seja, o possível predomina sobre o nccessário;

b) ignorar as restrições e aventurar-se em busca do impossivel, neste caso, prevalece o voluntarismo emocional e doutrinário; $\mathrm{e}$

c) não aceitar as restrições como definitivas e trabalhar com uma estratćgia para construir a viabilidade.

Neste último caso, a construção da viabilidade é feita a partir das informações contidas na matriz de motivações e na matriz de controle dos recursos. Havendo um ator contrário a uma operação e que exerça controle importante sobre algum recurso necessário, restam duas possibilidades:

a) tentar mudar a motivação do a tor, fazendo com que ele fique neutro ou a favor da operação; e

b) enfraquecer o controle que o ator exerce sobre o recurso necessário

Em termos práticos, isso significa mudar as configurações das matrizes de controle dos recursos e de motivações. Para isso, podem ser usados certos meios estratégicos que se classificam genericamente em imposição, interação cooperativa e interação conflitiva.

Imposição. A imposição é baseada na autoridade e na hierarquia, e supõe que alguns 
atores são dependentes de outros, aos quais devem obediência. Quando se usa exageradamente a imposição, sem acompanhamento de outros tipos de estratégias, há desgaste e perda de poder por parte daquele que exerce a autoridade.

Interação cooperativa. Ocorre quando as partes estão dispostas a colaborar entre si, para alcançarem objetivos comuns, mesmo com o sacrifício de alguns objetivos pessoais. No jogo de cooperaçào prevalecem a persuasão, as negociações, os acordos, os ânimos para diluir conflitos e a criação de instâncias para prevenir atritos. O jogo cooperativo exige que as opções de jogadas apresentem possibilidades de mútuo benefício e se baseia em relações de confiança entre os jogadores.

Interação conflitiva. Predominam a desconfiança, a oposição e a demonstração de forças. As jogadas são feitas sempre no sentido de desgastar, enfraquecer ou restringir as chances do outro. Há três intensidades de conflitos: (1) dissuasão - é feita com exibição de forças e demonstração da disposição de usá-las, se necessário; (2) confrontação há medição não-violenta de forças, como ocorre em casos de apostas e votações; e (3) guerra - caracteriza-se pela violência, com medição de forças bélicas.

\section{Assessoria Tecnopolítica}

Analisando-se três mil decisões tomadas por um governante latinoamericano e classificando-as em quatro niveis de importância, Matus descobriu a distribuição apresentada na Fig. 11.

\begin{tabular}{l|r|r}
\hline GRAU DE IMPORTÂNCIA & \multicolumn{1}{|c|}{ QUANT. } & \multicolumn{1}{|c}{$\%$} \\
\hline Decisões muito importantes & 5 & 0,2 \\
\hline Decisōes importantes & 45 & 1,5 \\
\hline Decisões significativas & 300 & 10,0 \\
\hline Decisōes rotineiras & 2.650 & 88,3 \\
\hline \multicolumn{1}{c|}{ TOTAL } & 3.000 & 100,0 \\
\hline
\end{tabular}

Fig. 11. Grau de importância de 3.000 decisões tomadas por um dirigente.

Isso significa que menos de $2 \%$ das decisões desse dirigente podem ser classificadas como importantes. Observou-se também que aquelas decisões menos importantes competem, com peso equivalente, na ocupação do tempo do dirigente. Muitas dessas decisões resultam de desdobramentos de problemas que não foram resolvidos no momento adequado e acabaram se transformando em urgências. Essas decisões urgentes geralmente são de má qualidade, pois basciam-se em visões de curto prazo, não se apoiam em análises situacionais e, dificilmente, resolvem o problema, criando apenas paliativos para o mesmo.

Com a aplicação do PES torna-se possivel criar, junto ao gabinete do dirigente, uma assessoria tecnopolítica treinada para orientar o mesmo nas decisões importantes. Essa assessoria deve trabalhar também na organização de uma agenda para o dirigente, de modo que pelo menos $20 \%$ do tempo dele seja dedicado aos assuntos importantes.

Os assuntos menos importantes (aqueles que não se incluem na árvore do problema) devem ser encaminhados para os escalões intermediários e inferiores da hierarquia. Como regra geral, as decisões devem ser tomadas preferencialmente ao nível em que elas possam ser tratadas criativamente. $\mathrm{Ou}$ 
seja, por aqueles que tenham sensibilidade e conheçam as implicações das decisões a serem tomadas. Do contrário, essas decisões se transformam em meras rotinas burocráticas. Por esse critério muitas decisões devem descer de nivel, mas há também casos inversos. Decisões de caráter amplo devem subir na hierarquia pois, se tomadas em escalões inferiores, tendem a fracionar as soluções, prejudicando o desempenho global e harmonioso do sistema.

Os estrategistas devem considerar também as principais surpresas que poderão ocorrer e, quando isso acontecer, devem estar preparados com as respectivas "saidas" de emergência ou planos de contingência. Um plano de contingência é, por exemplo, a escada que substitui os elevadores quando há falta de eletricidade.

As surpresas podem provocar crises, que são caractcrizadas por emergências, tensões, alta velocidade dos acontecimentos e necessidade de tomar decisões com baixo nivel de informações, associada à baixa qualidade de processamento das mesmas. Durante as crises, muitos canais regulares tornam-se inoperantes. É necessário, então, mobilizar pessoas treinadas no manejo de crises, com utilização de sistemas alternativos de informação para reduzir a súbita cegueira situacional que afeta os atores envolvidos nessas crises.

\section{Conclusões}

A atividade de planejamento foi bastante desacreditada nos últimos anos, tanto pelo uso inadequado de modelos tradicionais, como pelo distanciamento entre os planejadores e os executores.
O Planejamento Estratégico Situacional propõe-se a corrigir essas duas falhas. Ele apresenta um instrumento flexivel, adequado para explicar as realidades complexas. Um plano elaborado com a aplicação do PES nunca é uma obra "fechada", mas uma espécie de "mapa" para dirigir o ator, para que as suas ações possam ser mais efetivas em cada momento da ação.

Este artigo não tem a pretensão de esgotar o assunto, mas apresentar apenas os conceitos gerais do PES, desenvolvidos por Carlos Matus, para que os eventuais interessados possam se aprofundar no estudo do mesmo.

\section{Referências Bibliográficas}

CASTILLO, L. C., El PES en sintesis, Revista $P E S$, n. 1, p. 61-70, 1992.

MATUS, C., Adiós, señor Presidente, Caracas: Editorial Pomaire Venezuela S.A., 1987

MATUS, C., El líder sin Estado Mayor, Revista PES, n.1, p. 9-60, 1992

MATUS, C. , El plan como Apuesta,Revista PES, n.2, p. 9-59, 1993

Nota: A Revista PESé publicada pela Fundação Altadir, com sede na Avenida Francisco de Miranda, Torre Europa, Pl. Especial, Oficina 20, Caracas, Venezuela, Tel.: 9514091, 9512059, 9511764 . Fax: 9515498. 